\title{
Accuracy of genomic prediction for milk production traits in the Chinese Holstein population using a reference population consisting of cows
}

\author{
X. Ding, ${ }^{* 1}$ Z. Zhang, ${ }^{*} \dagger^{1}$ X. Li, ${ }^{* 1}$ S. Wang, ${ }^{*} X$. Wu, ${ }^{*}$ D. Sun, ${ }^{*} Y . ~ Y u,{ }^{*}$ J. Liu, ${ }^{*} Y$. Wang, ${ }^{*} Y$. Zhang, ${ }^{*}$ S. Zhang, ${ }^{*}$ \\ Y. Zhang, ${ }^{*}$ and Q. Zhang ${ }^{* 2}$ \\ *Laboratory of Animal Genetics, Breeding and Reproduction, Ministry of Agriculture of China, National Engineering Laboratory \\ for Animal Breeding, College of Animal Science and Technology, China Agricultural University, Beijing 100193, China \\ †Guangdong Provincial Key Laboratory of Agro-Animal Genomics and Molecular Breeding, College of Animal Science, \\ South China Agricultural University, Guangzhou, 510642, China
}

\section{ABSTRACT}

Genomic selection using dense markers covering the whole genome is a tool for the genetic improvement of livestock and is revolutionizing the breeding system in dairy cattle. Progeny-tested bulls have been used to form reference populations in almost all countries where genomic selection has been implemented. In this study, the accuracy of genomic prediction when cows are used to form the reference population was investigated. The reference population consisted of 3,087 cows. All individuals were genotyped with Illumina BovineSNP50. After genotype imputation and editing, 48,676 single nucleotide polymorphisms were available for analysis. Two methods, genomic BLUP (GBLUP) and BayesB, were used to render genomic estimated breeding values (GEBV) for 5 milk production traits. Accuracies of GEBV were assessed in 3 ways: $r_{\text {GEBV,EBV }}$ (the correlation between GEBV and conventional EBV) in 67 progeny-tested bulls, $\mathrm{r}_{\mathrm{GEBV}, \mathrm{EBV}}$ from a 5-fold cross validation in the 3,087 cow reference population, and the theoretical accuracy (for GBLUP) calculated in the same way as for conventional BLUP. The results showed that using GBLUP, the $\mathrm{r}_{\mathrm{GEBV}, \mathrm{EBV}}$ and theoretical accuracy of genomic prediction in Chinese Holstein ranged from 0.59 to 0.76 and 0.70 to 0.80 , respectively, which was 0.13 to 0.30 and 0.23 to 0.33 higher than the accuracies of conventional pedigree index, respectively. The results indicate that, as an alternative, genomic selection using cows in the reference population is feasible.

Key words: genomic selection, Chinese Holstein, cow, cross validation

\footnotetext{
Received September 24, 2012.

Accepted March 25, 2013.

${ }^{1}$ These authors contributed equally to this work.

${ }^{2}$ Corresponding author: qzhang@cau.edu.cn
}

\section{INTRODUCTION}

Genomic selection (GS) is revolutionizing animal breeding. It differs from traditional selection methods, in which phenotypes and pedigree are combined to predict the genetic merit of each individual in pedigree, as GS estimates the genetic merit of all genotyped individuals based on the estimates of marker effects (Meuwissen et al., 2001) or on the relationship derived from whole-genome dense markers (VanRaden, 2008). A significant advantage of GS over parent average is that the prediction accuracy on selection candidates is higher (Hayes et al., 2009). In addition, the breeders benefit from a substantial reduction of generation interval in GS, especially for those species with long generation interval (e.g., dairy cattle; Schaeffer, 2006; König et al., 2009). Genomic selection has been widely investigated in animal (Goddard and Hayes, 2009), plant (Heffner et al., 2009), and aquaculture (Nielsen et al., 2009) breeding and implemented in several species, such as barley (Zhong et al., 2009), chicken (González-Recio et al., 2009), mice (Legarra et al., 2008), pig (Cleveland et al., 2010), and especially dairy cattle (VanRaden et al., 2009; Verbyla et al., 2009; Su et al., 2010). For dairy cattle, the economic efficiency and annual genetic gain could be increased substantially if GS was completely implemented (Schaeffer, 2006; König et al., 2009).

A reference population of sufficient size is the first requirement for GS, in which all individuals are genotyped with an SNP chip and phenotyped for traits of interest. For dairy cattle, in almost all countries with a developed dairy industry, progeny-tested bulls are usually used to form the reference population, and their highly reliable conventional EBV (predicted from performance records of their daughters; VanRaden et al., 2009; Su et al., 2010), daughter yield deviations (Luan et al., 2009; Habier et al., 2010), or deregressed proofs (Garrick et al., 2009; Liu et al., 2011) are usually used as phenotypes in GS. However, forming this kind of reference population is not feasible in some countries (e.g., in China, where insufficient progeny-tested bulls 
are available). In China, only a small number of young bulls (ranging from 50 to 200) were progeny tested each year in the past 10 yr. Currently, less than 200 progenytested bulls exist that have highly reliable EBV (reliability $>0.80$ ) and are also available for genotyping. Therefore, as an alternative, cows were used to form the reference population, although their conventional EBV are not highly reliable compared with progeny-tested bulls. Similar situations exist when implementing GS in other livestock species, such as pig and beef cattle. The accuracy of genomic prediction in such cases is not clear and needs to be investigated.

In China, studies on genomic selection in Chinese Holsteins have been ongoing since 2009. A reference population has been built and continuously updated, which mainly comprises cows. In this study, the preliminary investigation on accuracies of genomic estimated breeding values (GEBV) using a reference set consisting only of cows is reported.

\section{MATERIALS AND METHODS}

\section{Population and Phenotypes}

A reference population and a validation population of Chinese Holstein cattle were established. The reference population consisted of 3,087 cows with complete dairy herd improvement records of at least 1 lactation. These cows were born between 2001 and 2007 (Table 1), originated from 22 sire families (83-358 daughters in each family with an average of 150), and were from 29 farms in the Beijing area. The validation population consisted of 67 progeny-tested bulls born between 1993 and 2002 (older than the cows in the reference population) and did not have daughters in the reference population.

Five milk production traits were analyzed, including milk yield, fat yield, fat percentage, protein yield, and protein percentage. The current official EBV were used as phenotypes. These EBV were obtained based on a multiple trait random regression test-day model (Schaeffer et al., 2000). The descriptive statistics of the EBV for the 5 traits are presented in Table 2. All 5

Table 1. Numbers of cows in the reference population born in different years

\begin{tabular}{lc}
\hline $\begin{array}{l}\text { Year of } \\
\text { birth }\end{array}$ & $\begin{array}{l}\text { Cows } \\
\text { (no.) }\end{array}$ \\
\hline$<2003$ & 366 \\
2003 & 538 \\
2004 & 721 \\
2005 & 765 \\
2006 & 468 \\
2007 & 229 \\
\hline
\end{tabular}

Table 2. Descriptive statistics of EBV for 3,087 cows for 5 milk production traits in Chinese Holstein

\begin{tabular}{lrrrr}
\hline Trait & Mean & \multicolumn{1}{c}{ SD } & Minimum & Maximum \\
\hline Milk yield $(\mathrm{kg})$ & 409.24 & 635.25 & $-1,684.00$ & $2,643.00$ \\
Fat yield $(\mathrm{kg})$ & 7.21 & 25.27 & -76.00 & 107.00 \\
Fat percentage & -0.08 & 0.26 & -1.00 & 0.91 \\
Protein yield $(\mathrm{kg})$ & 11.95 & 18.23 & -50.00 & 82.00 \\
Protein percentage & -0.01 & 0.09 & -0.42 & 0.43 \\
\hline
\end{tabular}

traits were assigned the same accuracies of EBV. The accuracies of EBV of the 3,087 cows varied from 0.45 to 0.72 with an average of 0.60 , and the accuracies of EBV of the 67 bulls ranged from 0.92 to 0.99 with an average of 0.97 .

\section{Genomic Data}

All individuals in the reference and validation population, as well as the sires of cows in the reference population, were genotyped with the Illumina Bovine SNP50 BeadChip (Illumina, San Diego, CA) version 1 (containing 54,001 SNP) or version 2 (containing $54,609 \mathrm{SNP}$ ). The chips have 52,340 SNP in common and 56,270 SNP in total in the 2 versions. We imputed the missing genotypes in either version 1 or version 2 using BEAGLE (Browning and Browning, 2009), so that all individuals had genotypes of the same set of SNP. For the imputation, genotype information of the sires of the reference cows were also used to improve the accuracy of imputation. The missing genotypes of SNP with unknown genomic position were replaced with heterozygotes. After imputation, SNP with minor allele frequency less than 0.01 and individuals with call rates less than 0.90 were removed; after quality control, 48,676 SNP and 3,087 reference cows remained for GEBV calculation. The minor allele frequency of SNP after quality control are illustrated in Figure 1.

\section{Statistical Model}

Two methods, BayesB (Meuwissen et al., 2001) and genomic BLUP (GBLUP; VanRaden, 2008), were implemented to predict GEBV for each genotyped individual.

BayesB. The statistical model of BayesB can be written as

$$
\mathbf{y}=\mu \mathbf{1}_{n}+\sum_{i=1}^{N} \mathbf{z}_{i} g_{i}+\mathbf{e}
$$

where $\mathbf{y}$ is the vector of phenotypic values; $\mu$ is the overall mean; $\mathbf{1}_{n}$ is a vector of $n$ ones; $g_{i}$ is the random effect of the $i$ th marker with a distribution of $N\left(0, \sigma_{g_{i}}^{2}\right)$; 


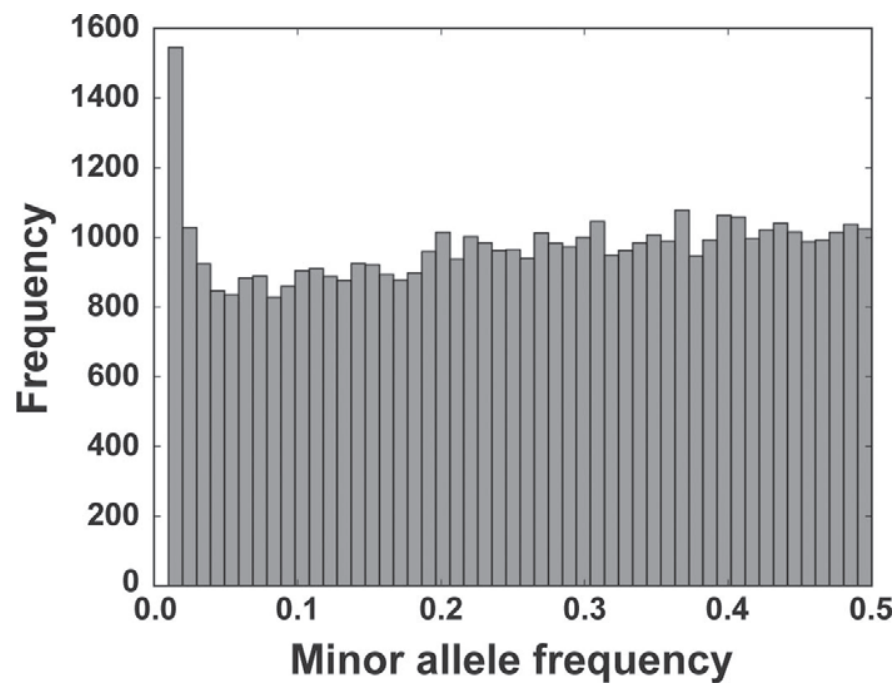

Figure 1. Minor allele frequencies of SNP after imputation and quality control.

$N$ is the total number of markers; $\mathbf{z}_{i}$ is the design vector corresponding to $g_{i}$, in which the genotypes of SNP with alleles 1 and 2 are represented as 0,1 , and -1 to denote the heterozygote (12) and the 2 different homozygotes (22 and 11), respectively; and $\mathbf{e}$ is the vector of residual errors with a distribution of $N\left(0, \sigma_{e}^{2}\right)$. The variance of the marker effects, $\sigma_{g_{i}}^{2}$, was assumed to be zero with a probability of $\pi$ (typically large) or follow a scaled inverse Chi-squared distribution with a probability of $(1-\pi)$. To investigate the effect of $\pi$ on the accuracy of GEBV, 4 levels of $\pi(0.99,0.95,0.80$, and 0.50) were used. Following Zhang et al. (2011), the Markov chain Monte Carlo (MCMC) chain was run for 10,000 cycles with 100 cycles of Metropolis-Hastings sampling in each Gibbs sampling, and the first 2,000 cycles were discarded as burn-in. All the samples of marker effects from the later 8,000 cycles were averaged to obtain the estimates of marker effects. The GEBV of a genotyped individual was calculated as the sum of all marker effects according to its marker genotypes (Meuwissen et al., 2001).

$\boldsymbol{G B L} \boldsymbol{U P}$. For GBLUP, the GEBV of all genotyped individuals were predicted by solving the mixed model equations based on the following model:

$$
\mathbf{y}=\mu \mathbf{1}_{n}+\mathbf{Z u}+\mathbf{e},
$$

where $\mathbf{Z}$ is an incidence matrix, $\mathbf{u}$ is the vector of genomic breeding values of all genotyped individuals with the distribution of $N\left(0, \mathbf{G} \sigma_{u}^{2}\right)$, where $\mathbf{G}$ is the genomic relationship matrix and was constructed using all markers following VanRaden (2008). The software, DMU
(Madsen et al., 2010), was used to estimate variance components and to obtain solutions of the mixed model equations.

\section{Evaluation of Accuracy of GEBV}

The accuracies of GEBV were evaluated as the correlation between GEBV and conventional EBV $\left(\boldsymbol{r}_{\mathrm{GEBV}, \mathrm{EBV}}\right)$ of the progeny-tested bulls in the validation population, as well as of the cows in the reference population through a cross validation. For the cross validation, a 5 -fold cross validation was applied to the 3,087 cows. These cows were divided into 5 groups according to their birth year (Table 1), that is, cows born before 2003, in 2003, 2004, 2005, and after 2005 were assigned into groups 1 to 5, respectively. Each group was treated as a validation group in turn and the others as a reference group. For each cross validation, $r_{\mathrm{GEBV}, \mathrm{EBV}}$ was calculated for individuals in the validation group. Additionally, for GBLUP, the theoretical accuracy of GEBV can be calculated for each individual in the same way as in the conventional BLUP following Henderson (1975). So, the average theoretical accuracy was also used to evaluate the accuracy of GBLUP.

\section{RESULTS}

\section{Influence of the Prior $\pi$ on the Accuracy of GEBV and Estimates of Marker Effects from Bayes $B$}

Accuracies of GEBV through cross validation using BayesB with 4 different priors for $\pi(0.99,0.95$, 0.80 , and 0.50 ) are shown in Table 3. In general, the variation of the accuracies is small when different $\pi$ values are used. For milk yield and protein yield, the accuracies were slightly decreased with the increase of $\pi$, whereas, for the other traits, the accuracies were slightly increased with the increase of $\pi$.

The distribution of the estimated marker effects varied with different priors for $\pi$ (Figure 2). It is obvious that more estimated marker effects were shrunk toward zero when the value of $\pi$ increased. Accordingly, markers with a small effect would be hardly observed, as illustrated in Figure $3(\pi=0.95)$, where the estimated effects of all markers were plotted against their positions in the Bovine genome. For all traits, the vast majority of estimated marker effects were shrunk toward zero, and only a few markers were assigned a notable effect. Among these SNP, the one near the DGAT1 gene (Grisart et al., 2004), named ARS-BFGL-NGS-4939 in the Illumina BovineSNP50 annotation file and located at $443,937 \mathrm{bp}$ on chromosome 14, showed the highest influence on all traits except protein yield. 
Table 3. Correlation between genomic EBV and EBV ( $\mathrm{r}_{\mathrm{GEBV}, \mathrm{EBV}}$ ) for cows in the 5-fold cross-validation procedure using BayesB with different priors for $\pi$

\begin{tabular}{|c|c|c|c|c|c|}
\hline \multirow[b]{2}{*}{ Trait } & \multirow[b]{2}{*}{ Data set ${ }^{1}$} & \multicolumn{4}{|c|}{$\mathrm{r}_{\mathrm{GEBV}, \mathrm{EBV}}$} \\
\hline & & $\pi=0.5$ & $\pi=0.8$ & $\pi=0.95$ & $\pi=0.99$ \\
\hline \multirow[t]{6}{*}{ Milk yield (kg) } & Test1 & 0.395 & 0.394 & 0.398 & 0.367 \\
\hline & Test2 & 0.433 & 0.432 & 0.434 & 0.404 \\
\hline & Test3 & 0.412 & 0.412 & 0.411 & 0.400 \\
\hline & Test 4 & 0.408 & 0.407 & 0.404 & 0.395 \\
\hline & Test5 & 0.284 & 0.280 & 0.272 & 0.257 \\
\hline & Average & 0.386 & 0.385 & 0.380 & 0.364 \\
\hline \multirow[t]{6}{*}{ Fat yield (kg) } & Test1 & 0.350 & 0.353 & 0.351 & 0.337 \\
\hline & Test2 & 0.319 & 0.321 & 0.324 & 0.332 \\
\hline & Test3 & 0.339 & 0.341 & 0.344 & 0.348 \\
\hline & Test4 & 0.324 & 0.326 & 0.333 & 0.344 \\
\hline & Test5 & 0.405 & 0.404 & 0.405 & 0.401 \\
\hline & Average & 0.347 & 0.349 & 0.351 & 0.352 \\
\hline \multirow[t]{6}{*}{ Fat percentage } & Test1 & 0.567 & 0.570 & 0.576 & 0.575 \\
\hline & Test2 & 0.501 & 0.503 & 0.504 & 0.496 \\
\hline & Test3 & 0.531 & 0.532 & 0.535 & 0.537 \\
\hline & Test4 & 0.517 & 0.518 & 0.519 & 0.514 \\
\hline & Test5 & 0.485 & 0.486 & 0.488 & 0.486 \\
\hline & Average & 0.520 & 0.522 & 0.525 & 0.522 \\
\hline \multirow[t]{6}{*}{ Protein yield (kg) } & Test1 & 0.321 & 0.323 & 0.327 & 0.323 \\
\hline & Test2 & 0.429 & 0.424 & 0.416 & 0.386 \\
\hline & Test3 & 0.350 & 0.351 & 0.352 & 0.350 \\
\hline & Test4 & 0.384 & 0.383 & 0.383 & 0.382 \\
\hline & Test5 & 0.302 & 0.300 & 0.294 & 0.283 \\
\hline & Average & 0.357 & 0.356 & 0.355 & 0.345 \\
\hline \multirow[t]{6}{*}{ Protein percentage } & Test1 & 0.454 & 0.466 & 0.479 & 0.468 \\
\hline & Test2 & 0.393 & 0.414 & 0.436 & 0.427 \\
\hline & Test3 & 0.420 & 0.427 & 0.418 & 0.412 \\
\hline & Test 4 & 0.422 & 0.429 & 0.444 & 0.450 \\
\hline & Test5 & 0.363 & 0.364 & 0.368 & 0.370 \\
\hline & Average & 0.410 & 0.420 & 0.429 & 0.425 \\
\hline
\end{tabular}

${ }^{1}$ Birth year of cows in the 5 data sets: Test $1=$ before 2003 ; Test $2=2003$; Test $3=2004$; Test $4=2005$; Test5 $=2006-2007$.

\section{Accuracy of GEBV}

The accuracies of GEBV measured in the progenytested bulls of the validation population from BayesB $(\pi=0.95)$ and GBLUP are shown in Table 4 . In the 3,087-cow reference population scenario, the $\mathrm{r}_{\mathrm{GEBV}, \mathrm{EBV}}$ from GBLUP (ranging from 0.594-0.760) was higher than that from BayesB (ranging from 0.570-0.731) for all traits except fat percentage. For GBLUP, the average theoretical accuracy ranged from 0.70 to 0.80 and was higher than the corresponding $\mathrm{r}_{\mathrm{GEBV} \text {,EBV }}$ for all traits except milk yield, for which $\mathrm{r}_{\mathrm{GEBV} \text { EBV }}$ was 0.01 higher than the theoretical accuracy. Table 4 also presents the accuracy of genomic prediction when the first batch of 2,093 genotyped cows was used to form the reference population. It can be seen that when the reference population was enlarged from 2,093 to 3,087 , the $\mathrm{r}_{\mathrm{GEBV}, \mathrm{EBV}}$ increased by 0.10 to 0.16 and 0.01 to 0.11 for almost all traits for GBLUP and BayesB, respectively. One exception was fat percentage, for which no improvement for BayesB and a tiny increase for GBLUP were observed. For GBLUP, the average theoretical accuracy was improved by 0.08 to 0.10 for all traits. BayesB performed better than GBLUP in the 2,093-cow reference population scenario.

Table 5 shows the accuracies of BayesB and GBLUP from the cross validation. BayesB yielded 0.004 to 0.085 higher $\mathrm{r}_{\text {GEBV.EBV }}$ than GBLUP averaged over the 5 validation groups. Again, for GBLUP, the average theoretical accuracy was 0.20 to 0.36 higher than $\mathrm{r}_{\mathrm{GEBV}, \mathrm{EBV}}$.

\section{DISCUSSION}

A reference population consisting of 3,087 cows has been built in the Chinese Holstein genomic selection project since 2009 and this reference population will continue to grow. The accuracy of genomic selection was evaluated through a validation population with progeny-tested bulls, a 5 -fold cross validation with cows, and theoretical accuracy. The results demonstrate that genomic selection using cows to form the reference population is feasible. The accuracy of genomic prediction for milk production traits in the validation bulls ranged from 0.59 to 0.76 (Table 4 ), which was rela- 


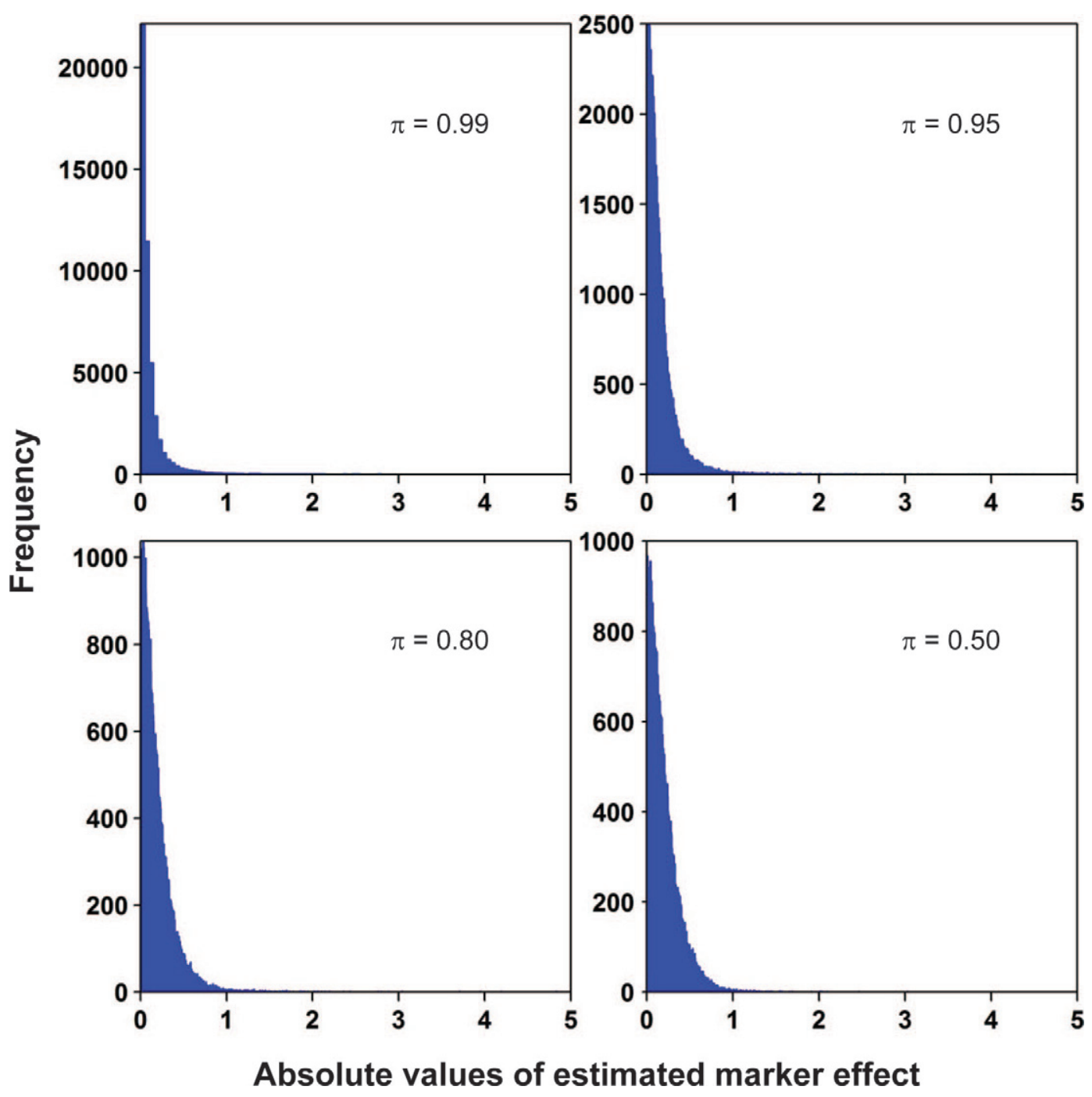

Figure 2. Frequency distribution of estimated marker effects for milk yield from BayesB with different $\pi$. A few SNP were observed with an effect greater than 5, but their frequencies were too small to be observed in the figure and therefore have been excluded from the figure. Color version available in the online PDF.

tively high compared with the accuracy of conventional pedigree index $(\mathbf{P I}$; calculated as $0.5 \times \mathrm{EBV}$ of sire + $0.25 \times \mathrm{EBV}$ of maternal grandsire), which is 0.464 on average for young bulls in Chinese Holstein for milk production traits. Using GBLUP, the $\mathrm{r}_{\mathrm{GEBV} \text {,EBV }}$ and the average theoretical accuracy in validation bulls were 0.13 to 0.30 and 0.23 to 0.33 higher than accuracies of PI, respectively. Therefore, genomic selection can significantly increase the accuracy for preselection of young bulls in comparison with traditional selection based on PI.

To date, in almost all countries carrying out genomic selection, progeny-tested bulls are used to set up the reference population. In China, the progeny-tested bulls available with sufficient accuracy of EBV are very limited, so, as an alternative, cows were used to form the reference population. The major advantage of using progeny-tested bulls over using cows to form reference population is that the EBV of the progenytested bulls have higher accuracies than the EBV of cows. The results presented were compared with those of some studies in which progeny-tested bulls were used to form reference population. In the study of Su et al. (2010) in Danish Holstein, a 5-fold cross validation was carried out for a reference population containing about 2,800 individuals. For each cross validation test the reference population contained 1,855 to 1,937 bulls with an average of 1,914 and the corresponding validation population varied from 538 and 456 bulls with an average of 479 . The accuracies $\left(\mathrm{r}_{\mathrm{GEBV}, \mathrm{EBV}}\right)$ of GEBV for milk production traits were 0.64 to 0.70 . In the study of Nieuwhof et al. (2010) in Australian 
Holsteins with a reference population of 1,873 bulls and a validation population of 320 younger bulls, the accuracies $\left(\mathrm{r}_{\mathrm{GEBV}, \mathrm{EBV}}\right)$ in the validation bulls were 0.75 across 3 milk production traits. In comparison with these results, the accuracies obtained in this study using a reference population with 3,087 cows are fairly comparable, whereas they are obviously lower than those with larger reference population size (e.g., about 16,000 progeny-tested bulls in EuroGenomics, where the reliability of GEBV obtained from EuroGenomics data was $11 \%$ higher on average than the reliability of GEBV from Nordic reference data alone; Lund et al.,
2010). In dairy cattle, some traits of low heritability (e.g., fertility traits) exist, for which the reliabilities of EBV are relatively low even for progeny-tested bulls. As the major difference between a cow reference population and a bull reference population lies in the reliabilities of EBV of the animals in the population, these results also provide a useful guide for genomic selection of traits of low heritability using a reference population consisting of bulls with EBV that are comparable to the reliability of cow EBV presented here.

Theoretically, the accuracy of GEBV is defined as the correlation between GEBV and true breeding value

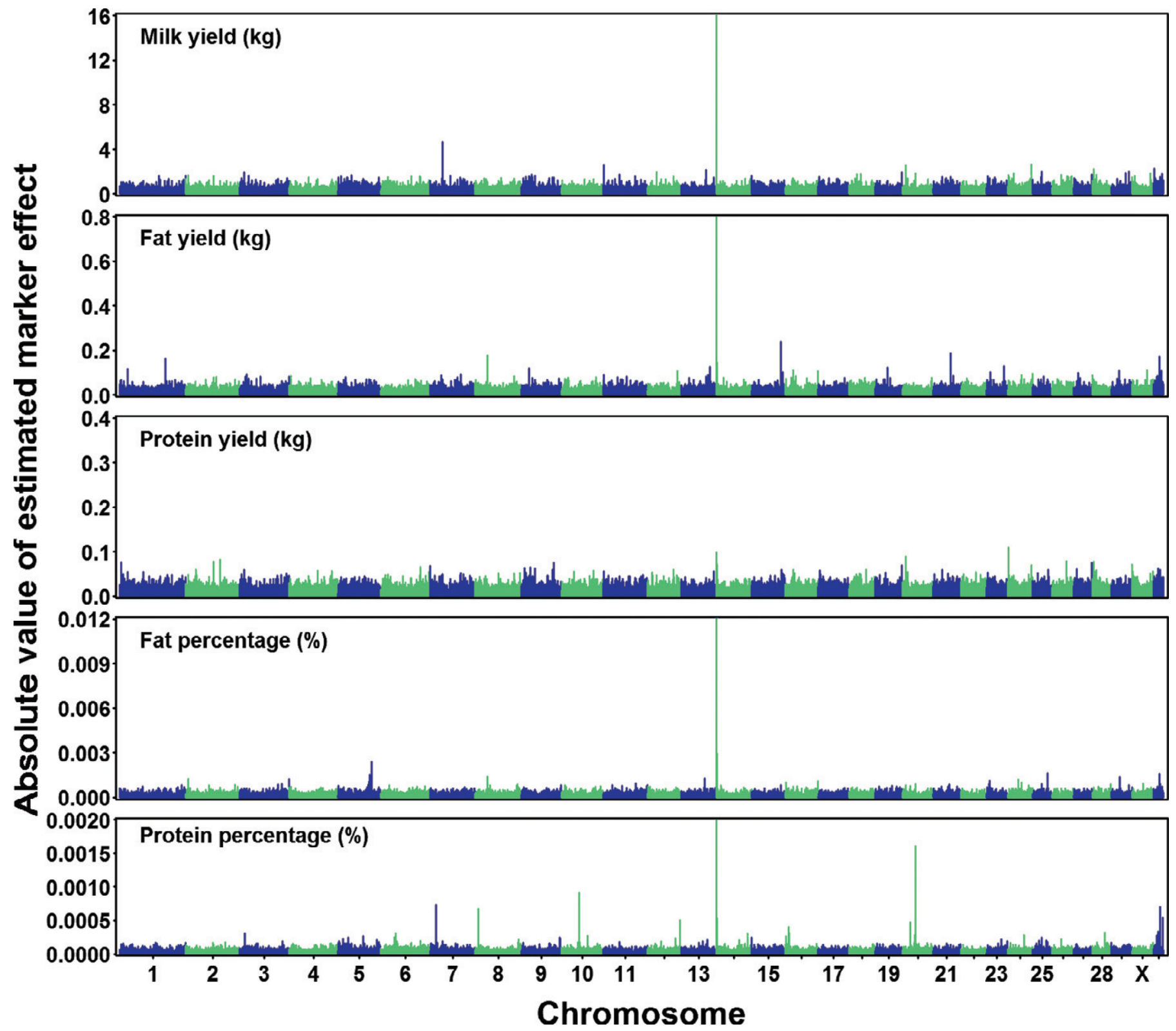

Figure 3. Estimated marker effects from BayesB $(\pi=0.95)$. Color version available in the online PDF. 
Table 4. Accuracy of genomic EBV from BayesB $(\pi=0.95)$ and genomic BLUP (GBLUP) in 67 progenytested bulls when reference populations of 3,087 (R1) and 2,093 (R2) cows are used

\begin{tabular}{|c|c|c|c|c|c|c|}
\hline \multirow[b]{3}{*}{ Trait } & \multicolumn{3}{|c|}{$\mathrm{R} 1$} & \multicolumn{3}{|c|}{$\mathrm{R} 2$} \\
\hline & \multirow{2}{*}{$\begin{array}{c}\text { BayesB } \\
\mathrm{r}_{\text {GEBV,EBV }}{ }^{1}\end{array}$} & \multicolumn{2}{|c|}{ GBLUP } & \multirow{2}{*}{$\begin{array}{c}\text { BayesB } \\
\mathrm{r}_{\mathrm{GEBV}, \mathrm{EBV}}\end{array}$} & \multicolumn{2}{|c|}{ GBLUP } \\
\hline & & $\mathrm{r}_{\mathrm{GEBV}, \mathrm{EBV}}$ & $\begin{array}{c}\text { Theoretical } \\
\text { accuracy }\end{array}$ & & $\mathrm{r}_{\mathrm{GEBV}, \mathrm{EBV}}$ & $\begin{array}{c}\text { Theoretical } \\
\text { accuracy }\end{array}$ \\
\hline Milk yield (kg) & 0.729 & 0.760 & 0.748 & 0.644 & 0.608 & 0.637 \\
\hline Fat yield (kg) & 0.610 & 0.641 & 0.790 & 0.505 & 0.489 & 0.699 \\
\hline Fat percentage & 0.710 & 0.678 & 0.762 & 0.710 & 0.669 & 0.657 \\
\hline Protein yield (kg) & 0.731 & 0.750 & 0.791 & 0.687 & 0.630 & 0.701 \\
\hline Protein percentage & 0.570 & 0.594 & 0.692 & 0.535 & 0.492 & 0.560 \\
\hline
\end{tabular}

${ }^{1} \mathrm{r}_{\mathrm{GEBV} . \mathrm{EBV}}=$ correlation between genetic EBV and conventional EBV.

(i.e., $\mathrm{r}_{\mathrm{GEBV} \text {.TBV }}$ ). In practice, the correlation of GEBV with $\mathrm{EBV}, \mathrm{r}_{\mathrm{GEBV}, \mathrm{EBV}}$, in a validation population or in the reference population through a cross validation, is widely used to measure the accuracy of GEBV.

In the present study, the validation population consisted of only 67 progeny-tested bulls and the $\mathrm{r}_{\mathrm{GEBV}, \mathrm{EBV}}$ might be subject to large sampling error due to the small validation population size. Furthermore, the progeny-tested bulls in the validation population are older than the reference cows, which does not reflect the scenario in real life where the accuracy of genomic selection should be a measure of accuracy for the selection of young candidates. For the cross validation, as the accuracy of EBV of the cows are relatively low (0.60 on average), the $\mathrm{r}_{\text {GEBV.EBV }}$ might not be a proper measurement of accuracy of GEBV. It should also be noted that although the reference cows were divided into 5 sets by their birth years, some relationships still exist between reference and validation sets, as all these cows are daughters of just 22 sires. This may lead the accuracy from such cross validation to be higher than the accuracy of GEBV for unrelated animals. Therefore, for GBLUP we calculated the theoretical accuracy for each individual through inverting the coefficient matrix of the mixed model equations (Henderson, 1975). It was found that the $\mathrm{r}_{\mathrm{GEBV} . \mathrm{EBV}}$ was lower than the average theoretical accuracies in both progeny-tested bulls and cross validation. This phenomenon was also observed in other studies (VanRaden et al., 2009; Su et al., 2010; Bijma 2012; Edel et al., 2012). The lower $\mathrm{r}_{\mathrm{GEBV}, \mathrm{EBV}}$ could be caused by the fact that EBV contain errors and the animals in the validation were selected from elite parents instead of random samples as discussed by VanRaden et al. (2009). Conversely, the theoretical accuracy may also be overestimated owing to sampling errors in elements of the genomic relationship matrix as pointed out by Goddard et al. (2011).

In applications of genomic selection, deregressed proofs (DRP) are more commonly used as response variables than EBV. Garrick et al. (2009) showed that DRP is theoretically more appropriate than EBV for 2 reasons. First, ancestral information is removed when calculating DRP and, thus, using DRP will reduce double-counting of parental information compared with using EBV. Second, using EBV may cause double shrinkage of genomic breeding values, particularly when the reliabilities of EBV are low. However, some studies also suggested using EBV (Guo et al., 2010; Gao et al., 2012; Thomasen et al., 2012). We also compared the performance of using DRP and EBV as response variable and found that using EBV performed slightly better than or equally compared with using DRP (unpublished data). This may be because the DRP was initially defined for deregressing EBV of bulls, and when used for EBV of

Table 5. Accuracies (mean and SE) of genomic EBV from BayesB and genomic BLUP (GBLUP) through cross-validation within the cow sample

\begin{tabular}{|c|c|c|c|}
\hline \multirow[b]{2}{*}{ Trait } & \multirow{2}{*}{$\frac{\text { BayesB }(\pi=0.95)}{\mathrm{r}_{\mathrm{GEBV}, \mathrm{EBV}}{ }^{1}}$} & \multicolumn{2}{|c|}{ GBLUP } \\
\hline & & $\mathrm{r}_{\mathrm{GEBV}, \mathrm{EBV}}$ & Theoretical accuracy \\
\hline Milk yield (kg) & $0.380(0.028)$ & $0.366(0.018)$ & $0.629(0.005)$ \\
\hline Fat yield (kg) & $0.351(0.014)$ & $0.317(0.016)$ & $0.675(0.004)$ \\
\hline Fat percentage & $0.525(0.015)$ & $0.440(0.013)$ & $0.644(0.005)$ \\
\hline Protein yield (kg) & $0.355(0.021)$ & $0.359(0.022)$ & $0.676(0.004)$ \\
\hline Protein percentage & $0.429(0.018)$ & $0.386(0.022)$ & $0.577(0.007)$ \\
\hline
\end{tabular}


cows some approximation has to be applied, which may reduce its superiority for genomic evaluation in the case that the reference population mainly comprises cows.

In the present study, only 5 milk production traits were analyzed, as many cows in the reference population do not have phenotypes on other traits (e.g., health, type, and fertility traits). The reference population will be updated continuously to increase the population size and phenotypes will be collected on more traits. So, GEBV for traits besides milk production traits will also be calculated in the future. In the interim, it is expected that if a sufficient amount of progeny-tested bulls are added to the current reference population, the accuracy of genomic prediction can be improved further. Along with increasing the number of progenytested bulls in China, as many progeny-tested bulls as possible will be added to the reference population. Very recently, the one-step model for genomic evaluation was proposed and has been proved to be more efficient than the two-step model because it can make use of information of animals without genotypes (Legarra et al., 2009; Misztal et al., 2009; Aguilar et al., 2010; Christensen and Lund 2010). The efficiency of the one-step model in the situation of Chinese Holstein will be investigated in the near future.

\section{CONCLUSIONS}

In this study we evaluated the accuracy of genomic prediction in Chinese Holstein cattle where the reference population was built only using cows. Using GBLUP, the $\mathrm{r}_{\mathrm{GEBV} \text {,EBV }}$ and the average theoretical accuracy in the progeny-tested bulls ranged from 0.59 to 0.76 and 0.70 to 0.80 , respectively, which were 0.13 to 0.30 and 0.23 to 0.33 higher than the accuracy of the conventional pedigree indices for young bulls. This indicates that genomic selection, in which cows are used to form the reference population, can be used for preselection of young candidate bulls in Chinese Holstein.

\section{ACKNOWLEDGMENTS}

This work was supported by the National '948' Project (2011-G2A), Ph.D. Programs Foundation of Ministry of Education of China (20110008110001), National Natural Science Foundation of China (31272418, 31200925), the earmarked fund for CARS-37, National Dairy Industry System in Beijing Team, Scientific Research Foundation for Returned Scholars, Ministry of Education of China, Program for Changjiang Scholar and Innovation Research Team in University (Grant No. IRT1191). We thank the Dairy Association of China (Beijing, China) for supplying the official EBV and Beijing Dairy Cattle Center (Beijing, China) for providing blood and semen samples.

\section{REFERENCES}

Aguilar, I., I. Misztal, D. L. Johnson, A. Legarra, S. Tsuruta, and T. J. Lawlor. 2010. Hot topic: A unified approach to utilize phenotypic, full pedigree, and genomic information for genetic evaluation of Holstein final score. J. Dairy Sci. 93:743-752.

Bijma, P. 2012. Accuracies of estimated breeding values from ordinary genetic evaluations do not reflect the correlation between true and estimated breeding values in selected populations. J. Anim. Breed. Genet. 129:345-358.

Browning, B. L., and S. R. Browning. 2009. A unified approach to genotype imputation and haplotype-phase inference for large data sets of trios and unrelated individuals. Am. J. Hum. Genet. $84: 210-223$.

Christensen, O. F., and M. S. Lund. 2010. Genomic prediction when some animals are not genotyped. Genet. Sel. Evol. 42:2.

Cleveland, M., S. Forni, D. Garrick, and N. Deeb. 2010. Prediction of genomic breeding values in a commercial pig population. Paper 266 in Proc. 9th World Congr. Genet. Appl. Livest. Prod., Leipzig, Germany. Gesellschaft für Tierzuchtwissenschaft e.V., Bonn, Germany.

Edel, C., S. Neuner, R. Emmerling, and K. U. Götz. 2012. A note on using 'forward prediction' to assess precision and bias of genomic predictions. Interbull Bull. 46:16-19.

Gao, H., M. S. Lund, Y. Zhang, and G. Su. 2012. Accuracy of genomic prediction using different models and response variables in the Nordic Red Cattle population. Pages 11-29 in Comparison of statistical models for genomic predictions in Nordic Dairy cattle populations. PhD Thesis of H. Gao. Aarhus University, Foulum, Denmark.

Garrick, D. J., J. F. Taylor, and R. L. Fernando. 2009. Deregressing estimated breeding values and weighting information for genomic regression analyses. Genet. Sel. Evol. 41:55.

Goddard, M. E., and B. J. Hayes. 2009. Mapping genes for complex traits in domestic animals and their use in breeding programmes. Nat. Rev. Genet. 10:381-391.

Goddard, M. E., B. J. Hayes, and T. H. Meuwissen. 2011. Using the genomic relationship matrix to predict the accuracy of genomic selection. J. Anim. Breed. Genet. 128:409-421.

González-Recio, O., D. Gianola, G. J. Rosa, K. A. Weigel, and A. Kranis. 2009. Genome-assisted prediction of a quantitative trait measured in parents and progeny: Application to food conversion rate in chickens. Genet. Sel. Evol. 41:3.

Grisart, B., F. Farnir, L. Karim, N. Cambisano, J. J. Kim, A. Kvaze, M. Mni, P. Simon, J. M. Frere, W. Coppieters, and M. Georges. 2004. Genetic and functional confirmation of the causality of the DGAT1 K232A quantitative trait nucleotide in affecting milk yield and composition. Proc. Natl. Acad. Sci. USA 101:2398-2403.

Guo, G., M. S. Lund, Y. Zhang, and G. Su. 2010. Comparison between genomic predictions using daughter yield deviation and conventional estimated breeding value as response variables. J. Anim. Breed. Genet. 127:423-432.

Habier, D., J. Tetens, F. R. Seefried, P. Lichtner, and G. Thaller. 2010. The impact of genetic relationship information on genomic breeding values in German Holstein cattle. Genet. Sel. Evol. 42:5.

Hayes, B. J., P. M. Visscher, and M. E. Goddard. 2009. Increased accuracy of artificial selection by using the realized relationship matrix. Genet. Res. (Camb.) 91:47-60.

Heffner, E. L., M. E. Sorrells, and J.-L. Jannink. 2009. Genomic selection for crop improvement. Crop Sci. 49:1-12.

Henderson, C. R. 1975. Best linear unbiased estimation and prediction under a selection model. Biometrics 31:423-447.

König, S., H. Simianer, and A. Willam. 2009. Economic evaluation of genomic breeding programs. J. Dairy Sci. 92:382-391.

Legarra, A., I. Aguilar, and I. Misztal. 2009. A relationship matrix including full pedigree and genomic information. J. Dairy Sci. 92:4656-4663. 
Legarra, A., C. Robert-Granie, E. Manfredi, and J. M. Elsen. 2008. Performance of genomic selection in mice. Genetics 180:611-618

Liu, Z., F. R. Seefried, F. Reinhardt, S. Rensing, G. Thaller, and R. Reents. 2011. Impacts of both reference population size and inclusion of a residual polygenic effect on the accuracy of genomic prediction. Genet. Sel. Evol. 43:19.

Luan, T., J. A. Woolliams, S. Lien, M. Kent, M. Svendsen, and T. H. E. Meuwissen. 2009. The accuracy of genomic selection in Norwegian red cattle assessed by cross-validation. Genetics 183:1119-1126.

Lund, M. S., A. P. W. d. Roos, A. G. d. Vries, T. Druet, V. Ducrocq, S. Fritz, F. Guillaume, B. Guldbrandtsen, Z. Liu, R. Reents, C. Schrooten, M. Seefried, and G. Su. 2010. Improving genomic prediction by EuroGenomics collaboration. Paper 880 in Proc. 9th World Congr. Genet. Appl. Livest. Prod., Leipzig, Germany. Gesellschaft für Tierzuchtwissenschaft e.V., Bonn, Gemany.

Madsen, P., G. Su, R. Labouriau, and O. F. Christensen. 2010. DMUA package for analyzing multivariate mixed models. Paper 732 in Proc. 9th World Congr. Genet. Appl. Livest. Prod., Leipzig, Germany. Gesellschaft für Tierzuchtwissenschaft e.V., Bonn, Gemany.

Meuwissen, T. H. E., B. J. Hayes, and M. E. Goddard. 2001. Prediction of total genetic value using genome-wide dense marker maps. Genetics 157:1819-1829.

Misztal, I., A. Legarra, and I. Aguilar. 2009. Computing procedures for genetic evaluation including phenotypic, full pedigree, and genomic information. J. Dairy Sci. 92:4648-4655.

Nielsen, H. M., A. K. Sonesson, H. Yazdi, and T. H. E. Meuwissen. 2009. Comparison of accuracy of genome-wide and BLUP breeding value estimates in sib based aquaculture breeding schemes. Aquaculture 289:259-264.

Nieuwhof, G. J., K. T. Beard, K. V. Konstantinov, P. J. Bowman, and B. J. Hayes. 2010. Implementation of genomics in Australia. Interbull Bull. 42:35-39.
Schaeffer, L. R. 2006. Strategy for applying genome-wide selection in dairy cattle. J. Anim. Breed. Genet. 123:218-223.

Schaeffer, L. R., J. Jamrozik, G. J. Kistemaker, and B. J. Van Doormaal. 2000. Experience with a test-day model. J. Dairy Sci. 83:1135-1144.

Su, G., B. Guldbrandtsen, V. R. Gregersen, and M. S. Lund. 2010. Preliminary investigation on reliability of genomic estimated breeding values in the Danish Holstein population. J. Dairy Sci. 93:1175-1183.

Thomasen, J. R., B. Guldbrandtsen, G. Su, R. F. Brøndum, and M. S. Lund. 2012. Reliabilities of genomic estimated breeding values in Danish Jersey. Animal 6:789-796.

VanRaden, P. M. 2008. Efficient methods to compute genomic predictions. J. Dairy Sci. 91:4414-4423.

VanRaden, P. M., C. P. Van Tassell, G. R. Wiggans, T. S. Sonstegard, R. D. Schnabel, J. F. Taylor, and F. S. Schenkel. 2009. Invited review: Reliability of genomic predictions for North American Holstein bulls. J. Dairy Sci. 92:16-24.

Verbyla, K. L., B. J. Hayes, P. J. Bowman, and M. E. Goddard. 2009. Accuracy of genomic selection using stochastic search variable selection in Australian Holstein Friesian dairy cattle. Genet. Res. (Camb.) 91:307-311.

Zhang, Z., X. Ding, J. Liu, Q. Zhang, and D. J. de Koning. 2011. Accuracy of genomic prediction using low-density marker panels. J. Dairy Sci. 94:3642-3650.

Zhong, S., J. C. M. Dekkers, R. L. Fernando, and J. L. Jannink. 2009. Factors affecting accuracy from genomic selection in populations derived from multiple inbred lines: A barley case study. Genetics 182:355-364. 